This is the final peer-reviewed accepted manuscript of:

Cevoli C.; Panarese V.; Catalogne C.; Fabbri A. "Estimation of the effective moisture diffusivity in cake baking by the inversion of a finite element model" which has been published in final form in JOURNAL OF FOOD ENGINEERING 2020, vol. 270, article n. 109769

The final published version is available online at:

https://doi.org/10.1016/i.jfoodeng.2019.109769

(C) 2020 Elsevier. This manuscript version is made available under the Creative Commons Attribution-NonCommercial-NoDerivs (CC BY-NC-ND) 4.0 International License (http://creativecommons.org/licenses/by-nc-nd/4.0/) 


\title{
Estimation of the effective moisture diffusivity in cake baking by the inversion of a finite element model
}

\author{
Chiara Cevoli $^{\mathrm{a}, *}{ }^{\text {, Valentina Panarese }}{ }^{\mathrm{b}}$, Angelo Fabbri ${ }^{\mathrm{a}}$ \\ a Department of Agricultural and Food Sciences, Alma Mater Studiorum, Università di Bologna, P.zza Goidanich 60, 47521, Cesena, FC, Italy \\ ${ }^{\mathrm{b}}$ Electrolux Italia S.P.A, Viale Bologna, 298, 47122, Forlì, FC, Italy \\ c Global Connectivity and Technology, Global Operations (GTandC) at Electrolux Italia S.p.a, Via L. Zanussi, 24, Porcia PN, 33080, Italy
}

\section{A R T I C L E I N F O}

\section{Keywords}

Moisture diffusion

Bakery

Inverse method

Numerical model

\begin{abstract}
A B S T R A C T
The moisture diffusivity of food is a very important physical parameter to model baking processes. Unfortunately, specific moisture diffusivity values are not easily found in literature, especially measured or calculated during the baking processes. The main methods used to estimate the moisture diffusivity are based on the second Fick's law, but there are significant differences in the way of applying these laws. The aim of this work is to estimate the effective moisture diffusivity in baking of a small flat cake by using the inversion of a numerical model based on the coupling of heat and mass transfer. The temperature and moisture dependency of the diffusivity is evaluated. Results are compared with those obtained by using a fitting method. The inverse method allows to estimate the effective moisture diffusivity close to those reported in literature for similar bakery products (constant values). The impact of the moisture concentration appears to be very restricted and it tends to decrease with increasing the oven temperature. Subsequently, the obtained effective diffusivity was implemented on a direct Finite Element (FE) model simulating a whole cake for different baking temperatures. The direct model validation (mean moisture content and temperature) shows determination coefficients ranging from 0.921 to 0.996 confirming the robustness of the diffusivity parameters obtained by the inverse method.
\end{abstract}

\section{Introduction}

Baking is the final and most important step in the bakery making. During the baking process physical, chemical and biochemical changes occur in the product, which are responsible for the final quality (Purlis, 2011). Temperature and moisture content are responsible for physiochemical and biological transformations such as browning reactions, evaporation of water, crust formation, gelatinization of starch, volume expansion and denaturation of proteins which make the baking a complex process (Chhanwal et al., 2012).

With the aim to reduce the trial and error effort involved in experimental test and to better understand the heat and mass transfer processes that take place during the baking, several numerical models simulating the baking process have been developed. The baking process models were developed combining appropriate heat and mass transfer equations: convective and radiative heat transfer on the product surface, internal heat conduction, internal moisture diffusion (either liquid or vapour), internal and surface evaporation and convective surface moisture removal mechanisms (Baik and Marcotte, 2003; Sakin et al., 2007a; Nicolas et al., 2014, 2017, ).The models can be classified into two categories: diffusive (Kokolj et al., 2017; Purlis, 2014; Purlis and Salvadori, 2009a, 2009b; Ureta et al., 2016; Sadeghi et al., 2016; Sakin et al., 2007a, 2007b; Tank et al., 2014) and multiphasic
(Lostie et al., 2004, 2002; Ousegui et al., 2010; Nicolas et al., 2014, 2017; Lucas et al., 2015; Zhang and Datta, 2006) models. In the first case, only temperature and moisture content are calculated, liquid and vapour phases are not separated and so a global diffusion coefficient is used; in the second case, the diffusion coefficient is not apparent but is calculated for each phase (liquid and vapour), the mass conservation is taken into account for each phase. In this last case the gas pressure can be introduced (Nicolas et al., 2014).

To obtain suitable models, especially for the diffusive models, a good knowledge of heat and moisture transport properties of baking products is essential. When using numerical models, the physical properties of heterogeneous product may be described by time/space/temperature/moisture-dependent variables (Fabbri et al., 2011, 2014). However, it is not easy to find in literature mass transfer food properties, compared to thermal ones, especially measured or calculated during the baking processes. As concerning the moisture diffusivity, this property strongly depends on temperature (Guillard et al., 2003) and on the moisture changes involved during the baking, due to the complex food structure related to starch and protein content, and their interaction with water. The main diffusivity estimation methods are based on Fick's laws, although there are significant differences in the implementation. For example, analytical solutions for various geometries or numerical solutions according to the spe-

\footnotetext{
* Corresponding author.

E-mail address: chiara.cevoli3@unibo.it (C. Cevoli)
} 
cific experimental conditions may be used; there is no standard method of evaluating the moisture diffusivity in food (Zogzas et al., 1994). Nevertheless, the most common method is based on the fitting of the experimental dimensionless drying data in a logarithmic form versus the baking time. Therefore, for a simple one-dimensional geometries, by assuming the first term approximation in the series solution, the diffusivity can be achieved from the slope of the linearized curve between experimental data and time (slope method) (Arranz et al., 2017).

This simple method allows to estimate constant diffusivity. So, to model the temperature effect, an Arrhenius type equation is commonly used, while the dependence of the moisture is introduced comparing the slopes of two curves at specific moisture ratio (Sakin et al., 2007a; Zogzas et al., 1994).

In recent years, numerical methods has become a quite used methodology to evaluate the moisture diffusivity even though there is not a standard procedure. Generally, the diffusivity is introduced in the numerical model through Fick's equations as a function of temperature or moisture content or any other material properties. The solution is found by fitting the numerical solution provided by the model to the measured data, by varying the model parameters. Indeed, the search for optimal parameters consists in finding the minimum of an objective function, defined by the distance between computed and measured values (Fabbri et al., 2014). Most of studies report the use of the finite difference methods, while very few research works are based on inversion of more complex and realistic finite element (FE) models. Nguyen et al. (2006) studied an estimation procedure of effective diffusivity in pear tissue by means of the inversion of numerical water diffusion model able to describe the water loss during storage. Moisture and temperature dependence was not taken into account. Mariani et al. (2008) proposed a stochastic method called Differential Evolution that optimizes the parameters of two equations as functions of dimensionless temperature and moisture. This procedure was used also by da Silva et al. (2009) and da Silva et al. (2010) to determine the diffusion coefficients during hot air drying of mushrooms and rough rice and by da Silva et al., 2010 to estimate the moisture coefficient during osmotic dehydration of the West Indian cherry (acerola). A method based on the inversion of finite element models, to estimate the moisture diffusivity in different solid food products (salami, biscuit and flat bread) during the hydration process, was proposed by Fabbri et al. (2014). In the recent work of Balzarini et al. (2018), the diffusivity of chicory root cubes was estimated by the inversion of a finite element model discribing the heat and mass transfer during the drying treatment. The diffusivity was implemented a function of product temperature and moisture content.

Concerning the moisture diffusivity of bakery products during baking, Baik and Marcotte (2003) determined the moisture diffusivity in a cake at four levels of oven temperature and five different amount of initial moisture contents. The slope method (only the first term of the series, $n=1$ ) was evaluated and a semi-empirical model as a function of porosity, temperature and moisture content of the cake was developed. Similarly, Sakin et al. (2007a) calculated the moisture diffusivity of a white cake baked at the oven temperatures of 50, 80, 100, 140 and $160^{\circ} \mathrm{C}$. The data were analyzed applying the method of slope ( $n=1)$ to drying curves; the diffusivity was related to the temperature and average moisture content of the cake batter. The temperature dependency of the moisture diffusivity followed an Arrhenius type equation, while the diffusivity increased with decreasing moisture content exponentially. The mass transfer parameters during baking were experimentally determined using mass changes of the baked cookies (under natural and forced convection conditions) by Demirkol et al. (2006). Three oven temperature were considered and the diffusivity was calculated by using the slope method $(n=1)$ to obtained a constant value and applying an infinite mass transfer coefficient approach (Erdoğ; du, 2005 ) to describe the diffusivity variation over the baking time. According to our knowledge, there are no studies on the application of inverse methods to estimate the diffusivity of bakery products during baking.

The aim of this work was to determine the effective moisture diffusivity of a bakery product (small flat cake) by using the inversion of a

element model. Simultaneous temperature and moisture content dependency was evaluated. The obtained diffusivity was used to solve a direct model. Experimental and calculated mean moisture content and temperature were compared.

\section{Materials and methods}

\subsection{Moisture diffusivity determination}

\subsubsection{Inverse method}

The diffusivity was determined by an inverse method, and the work was divided in three phases: I) experimental determination of the moisture concentration $\left(\bar{C}_{\text {exp }}\right)$ versus baking time; II) development of a $3 \mathrm{D}$ numerical model of the moisture and heat transfer in the cake during baking and numerical determination of the moisture concentration $\left(\bar{C}_{\text {num }}\right)$ vs time; III) definition of an Objective Function (OF) expressing the distance between numerical and experimental moisture concentration data, whose minimum drive to the calculation of $D$ value, following a classical parameter estimation scheme.

2.1.1.1. Experimental determination of the moisture concentration The batter cake was prepared using the following ingredients: flour (20.8\%), sugar $(31.2 \%)$, butter $(20.8 \%)$, pasteurized whole liquid eggs (15.6\%), milk $(10.4 \%)$ and baking powder (1.2\%). A three stage mixing method was employed using a kitchen mixer (Electrolux Kitchen Assistant EKM4800) equipped with a wire balloon whisk. Butter and sugar were mixed until white and soft color ( $5 \mathrm{~min}$ at maximum speed), subsequently the pasteurized whole liquid eggs were slowly added in 4 portions to the mixture while stirring for other $5 \mathrm{~min}$ at the maximum speed. The milk and the mix of flour and baking powder were finally added and the mixture was stirred for $2 \mathrm{~min}$ at slow speed. About $3 \mathrm{~mm}$ thin layer of batter was spread on cylindrical aluminum trays characterized by a diameters of $150 \mathrm{~mm}$. The very high thermal conductivity of the aluminum (about $230 \mathrm{~W} \mathrm{~m}^{-1} \mathrm{~K}^{-1}$ ) allowed a shorter lag times for isothermal baking. Cakes were baked in an domestic electric oven (Procombi Plus AEG, Germany) at $180^{\circ} \mathrm{C}$ under ventilated conditions (maximum air speed: $0.5 \mathrm{~m} \mathrm{~s}^{-1}$ ) until to reach the equilibrium moisture content. The humidity condition inside the oven cavity was remove with an air circulation system placed on the upper side of the oven. The moisture content $(X)$ was determined on 10 cakes for each combination of temperature and baking time $(5,10,15,20,25,30,35,40$ and $45 \mathrm{~min})$ by using a Thermo balance (i-Thermo $163 \mathrm{M}$, Exacta-Optech, Italy). For each sample cake, $5 \mathrm{~g}$ were dried at $130^{\circ} \mathrm{C}$ until constant weight. The protocol was validated by using the oven method reported in the standard AACC 44-15.02 $\left(130^{\circ} \mathrm{C}\right.$ for $\left.1 \mathrm{~h}\right)$. At the same baking time, the cake thickness (L) was measured by using a digital caliper (CDJB15 Borletti, Italy) on three random points.

2.1.1.2. Numerical determination of the moisture concentration The 2D-axisymmetric finite element model was developed using Comsol Multiphysics (COMSOL Inc., Burlington, MA). The geometric model replied the real dimensions and shapes of the samples used for the experimental test. The mass transfer was governed by the 2nd Fick's law:

$\frac{\partial C}{\partial t}=\nabla \cdot(D \nabla C)$

while the heat was transferred by conduction following the Fourier's equation:

$c_{p} \rho \frac{\partial T}{\partial t}=\nabla \cdot(k \nabla T)$

where:

$c_{p}=c_{p 1}, k=k_{1}$ and $\rho=\rho_{1}$ if $T \leq T_{e v}$

$c_{p}=c_{p 2}, k=k_{2}$ and $\rho=\rho_{2}$ if $T>T_{e v}$

being $T_{e v}$ the evaporation temperature $\left(100^{\circ} \mathrm{C}\right)$. Thermal properties $\left(k_{1,2}\right.$ and $c_{p 1,2}$ ) have been experimentally determined by using the needle probe KD2 (Decagon Device Inc., Pullman, USA) on the cake samples make during the 
experimental drying test. The density $\rho_{1,2}$ was also experimentally determined. The procedure proposed by Cevoli et al. (2014) was followed.As concerning the boundary conditions, flux conditions were imposed on the interface between the cake surface and the oven cavity air.Mass flux $\mathrm{n} \cdot(-D \nabla C)=N$

$$
=h_{m}\left(\frac{\mathrm{P}_{\mathrm{s}}}{\mathrm{RT}_{\mathrm{s}}}-\frac{\mathrm{P}_{\infty}}{\mathrm{RT}_{\infty}}\right) \text {, for the top surface }
$$

$\mathrm{n} \cdot(-D \nabla C)=N=0$, for the other boundaries

The mass transfer coefficient $h_{m}\left(\mathrm{~m} \mathrm{~s}^{-1}\right)$ was calculated on the basis of the well-known Chilton-Colburn analogy between the Nusselt number and the Sherwood number (Sh):

$h_{m}=\frac{S h D_{a}}{\mathrm{~L}}$

$S h_{t}=0.54\left(G r_{m} S c\right)^{\frac{1}{4}}$,

$S c=\frac{\mu_{a}}{\rho_{a} D_{a}}$

$G r_{m}=\frac{g L^{3} \rho_{a}\left(\rho_{a s}-\rho_{a \infty}\right)}{\mu_{a}^{2}}$

$\rho_{a s}=X_{s} \rho_{a}$

$\rho_{a \infty}=X_{\infty} \rho_{a}$

The vapour pressure in the oven far from the product surface $\left(P_{\infty}\right)$, and the vapour pressure close to cake surface $\left(P_{s}\right)$, are determined according to the vapour relative humidity in the oven far from the product surface $\left(R H_{\infty}\right)$ and the water activity at the interface $\left(a w_{s}\right)$, together with the corresponding temperature, via saturated vapour pressure $P_{\text {sat }}(T)$ given by Antoine's law:

$P_{\text {sat }}(T)=\left[10^{\left(8.07131-\frac{1730.63}{233.426+T}\right)} \frac{10^{5}}{760}\right]$

$P_{\infty}=R H_{\infty} P_{\text {sat }}\left(T_{\infty}\right)$

$R H_{\infty}=\left(\frac{\mathrm{X}_{\infty} \mathrm{P}_{\mathrm{atm}}}{0.622 \mathrm{P}_{\mathrm{sat}}\left(\mathrm{T}_{\infty}\right)+\mathrm{P}_{\mathrm{sat}}\left(\mathrm{T}_{\infty}\right) \mathrm{X}_{\infty}}\right)$

$X_{\infty}=0.622\left(\frac{R H_{a m b} P_{\text {sat }}\left(T_{a m b}\right)}{P_{a t m}-R H_{a m b} P_{\text {sat }}\left(T_{a m b}\right)}\right)$

$P_{s}=a w_{s} P_{s a t}\left(T_{s}\right)$

$a w_{s}=\left[\left(\frac{100 X_{d s}}{\exp (-0.0071 T+4.5)}\right)^{\frac{-1}{0.38}}+1\right]^{-1}$ (Zhang and Datta, 2006)

$X_{s}=\frac{C P M}{\rho_{d s}}$

Heat flux

$$
\begin{aligned}
\mathrm{n} \cdot(-k \nabla \mathrm{T})= & \mathrm{q} \\
= & h\left(\mathrm{~T}_{\infty}-\mathrm{T}\right)+\varepsilon \sigma\left(T_{\infty}^{4}-T^{4}\right) \\
& -N\left[c_{p v}\left(T-T_{r e f}\right)+L_{v}\right] P M_{H 2 O}
\end{aligned}
$$

where $h=1 / \vartheta$ is the overall heat transfer coefficient $\left(\mathrm{W} \mathrm{m}^{-2} \mathrm{~K}^{-1}\right)$ and the contact resistance $(\vartheta)$ can be calculated applying the concept of a thermal network:

$\vartheta=\sum \frac{d_{t r}}{k_{t r}}+\frac{1}{h_{C}}$

$d_{t r}(0.001 \mathrm{~m})$ and $k_{t r}\left(230 \mathrm{Wm}^{-1} \mathrm{~K}^{-1}\right)$ are the thickness and the thermal

con- ductivity of the tray, respectively. These parameters were taken into account only for the bottom and side cake surfaces in contact with the tray. The heat transfer coefficient $h_{c}\left(\mathrm{~W} \mathrm{~m}^{-2} \mathrm{~K}^{-1}\right)$ was obtained using the Nusselt number $(\mathrm{Nu})$ by the following equation:

$h_{c}=\frac{N u k_{a}}{\mathrm{~L}}$

The Nusselt number on the cake surface can be estimated from the equations for natural convection $\left(G r / \mathrm{Re}^{2}>1\right)$ in air at Rayleigh number $(R a)<10^{9}$ (Incropera et al., 2006):

$N u_{t}=0.27 R a^{1 / 4}$ for the top surface,

$N u_{b}=0.54 R a^{1 / 4}$ for the bottom surface

$N u_{w}=\frac{0.67 R a^{1 / 4}}{\left[1+(0.492 / P r)^{9 / 16}\right]^{4 / 9}}$ for the wall sides

$R a=G r P r$

$G r=\frac{g \beta L^{3} \rho_{a}^{2}\left(T_{s}-T_{\infty}\right)}{\mu_{a}^{2}}$

$\operatorname{Pr}=\frac{C_{p a} \mu_{a}}{k_{a}}$

Regarding heat transfer by radiation, the emissivity $(\varepsilon)$ of the cake was considered equal to 0.9 (Hamdami et al., 2004). $c_{p v}\left(1000 \mathrm{~J} \mathrm{~kg}^{-1} \mathrm{~K}^{-1}\right.$ ) is the specific heat of water vapour, $L_{v}$ is the water latent heat $\left(2256 \mathrm{~kJ} \mathrm{~kg}^{-1}\right)$ and $T_{\text {ref }}$ is the reference temperature equal to 273.15K.The mesh was made by 500 quadrilateral elements of which 8 layers of boundary elements characterized by a stretching factor of 1.2 (increase in thickness between two consecutive boundary layers) has been applied on the top boundary.The Arbitrary Lagarngian-Eulerian (ALE) approach was implemented in the model in order to account for cake expansion occurring during drying, as suggest also by Le Bideau et al. (2016) for cake baking, and by Seyedabadi et al. (2017) and Curcio and Aversa (2009) for others food processes. Usually, the moving mesh method was used to create models where the geometry changes shape due to some physical phenomena without material being removed or added. The difference between the deformed geometry and moving mesh is that the former defines a deformation of the material frame relative to the geometry frame, while the latter defines a displacement of the spatial frame relative to the material frame. In this case, a Laplace smoothing type to freely deformed domains was used and a free deformation procedure constraining the mesh displacement by the boundary conditions on the surrounding boundaries was taken into account. The displacement in the domain was obtained by solving a PDE. Particularly, a prescribe mesh displacement was incorporated in the model as a function of the moisture content on the base of experimental determinations.The values of the material properties and initial conditions are given in Table 1.

\subsection{Optimization procedure}

The distance between numerical and experimental data was considered as an Objective Function (OF), and defined as following:

$$
\begin{aligned}
O F(D) & =\int\left[\bar{C}_{\exp }(t)-\bar{C}_{\text {num }}(t, D)\right]^{2} d t \\
& \approx \sum_{i}\left[\bar{C}_{\exp }\left(t_{i}\right)-\bar{C}_{\text {num }}(t, D)\right]^{2}
\end{aligned}
$$

where $t_{i}$ represents the baking time steps used in the experimental tests.

It is accepted that the diffusion coefficient can be described by an exponential form considering the temperature and moisture dependence, so the temperature and moisture content dependency of the diffusivity was implemented in the model on the base of the equation proposed by (Baik and Marcotte, 2003; 
Table 1

Material properties implemented in the model.

\begin{tabular}{|c|c|c|c|}
\hline & Cake $\left(\mathrm{T} \leq 100^{\circ} \mathrm{C}\right)$ & $\begin{array}{l}\text { Cake } \\
\left(\mathrm{T}>100^{\circ} \mathrm{C}\right)\end{array}$ & Air \\
\hline $\begin{array}{l}\text { Thermal } \\
\text { conductivity, } k \\
\left(\mathrm{Wm}^{-1} \mathrm{~K}^{-1}\right)\end{array}$ & $3.65 \mathrm{E}-6 \mathrm{~T}^{3}-3.38 \mathrm{E}-3 \mathrm{~T}^{2}+1.05 \mathrm{~T}-1.07 \mathrm{E}+2$ & 0.07 & -2.2 \\
\hline $\begin{array}{l}\text { Density, } \rho \\
\left(\mathrm{kgm}^{-3}\right)\end{array}$ & $-7.37 \mathrm{E}-4 \mathrm{~T}^{3}+6.35 \mathrm{E}-1 \mathrm{~T}^{2}-1.823 \mathrm{~T}+1.827$ & 350 & $\begin{array}{l}\text { JAH } \\
346 .\end{array}$ \\
\hline $\begin{array}{l}\text { Specific heat, } \\
C_{P}\left(\mathrm{Jkg}^{-1} \mathrm{~K}^{-1}\right)\end{array}$ & $0.135 \mathrm{E}-6 \exp (0.0788 \mathrm{~T})$ & 4400 & $\begin{array}{l}\text { JAH } \\
1.05 \\
-6.0: \\
\text { JAH }\end{array}$ \\
\hline $\begin{array}{l}\text { Diffusion } \\
\text { coefficient, } D \\
\left(\mathrm{~m}^{2} \mathrm{~s}^{-1}\right)\end{array}$ & - & - & $\begin{array}{l}-2.7 \\
\text { JAH }\end{array}$ \\
\hline $\begin{array}{l}\text { Dynamic } \\
\text { viscosity, } \mu_{a} \\
\text { (Pas) }\end{array}$ & - & - & $\begin{array}{l}-75 \\
\text { JAH }\end{array}$ \\
\hline $\begin{array}{l}\text { Initial moisture } \\
\text { concentration, } \\
C\left(\text { molm }^{-3},\right. \\
\left.\mathrm{kg}_{\text {water }} \mathrm{kg}_{\text {solid }}{ }^{-1}\right)\end{array}$ & $7870,0.37$ & - & - \\
\hline
\end{tabular}

Sakin et al., 2007a):

$D(T, C)=A \exp \left(-\frac{B}{T}+E C\right)$

The optimal parameter $D$ value is the one which corresponds to the minimum of (least-squares errors criteria) and it was calculated by using the optimization module of Comsol Multiphysics. The calculation procedure was the same described by Fabbri et al. (2014). Levenberg-Marquardt method with the second order of numeric gradient method, was chosen as the optimization algorithm.

\subsubsection{Fitting method}

A constant diffusion coefficient was calculated by fitting the experimental data (see section 2.1.1.1) with the equation proposed by (Crank, 1975) for the analytical solution of the 2nd Fick's law:

$\frac{\bar{X}-X_{\infty}}{X_{0}-X_{\infty}}$

$=\frac{8}{\pi^{2}} \sum_{n=1}^{\infty}\left[\frac{1}{(2 n-1)^{2}} \exp \left(-\frac{(2 n-1)^{2} \pi^{2} D t}{4 l^{2}}\right)\right]$

The equation assumptions are: the cake was considered as an infinite slab, the initial moisture content $\left(X_{0}\right)$ was uniform and the moisture transfer was defined as one-dimensional (from the bottom toward the top). Considering up to 10 terms $(n \leq 10)$ as suggest by (Nicolin et al., 2016), the Levenberg-Marquardt (LM) algorithm was used to minimize the error between experimental and calculated data. The estimated parameters was $D$, the starting value was arbitrary set at $1 \mathrm{E}-10 \mathrm{~m}^{2} \mathrm{~s}^{-1}$, and a maximum number of 500 iterations were considered. Mean thickness value $(l=4.5 \mathrm{~mm})$ calculated on the base of experimental measurements were used. The procedure was repeat for the experimental data obtained at 140,160 and $180^{\circ} \mathrm{C}$ baking temperature and the effect of the cake temperature on the diffusivity value was reported with an Arrhenius type equation $\left(D=a \exp \left(-\frac{b}{T}\right)\right)$.

\subsection{Direct model}

A direct numerical model was developed to simulate a cylindrical whole cake characterized by the following dimensions: diameter of $0.26 \mathrm{~m}$ and initial height of $0.007 \mathrm{~m}$.

The governing equations and boundary conditions were the same described in section 2.1.1.2, only the tray thickness $(0.002 \mathrm{~m})$ and thermal conductivity ( $30 \mathrm{~W} \mathrm{~m}^{-1} \mathrm{~K}^{-1}$ ) have been changed. The volume expansion $\left(y=-504 X^{2}+192.7 X+5.9\right)$ was incorporated in the model as a function of the mean moisture content $(X)$ according to experimental determination (cake thickness was measured by using a digital caliper (CDJB15 Borletti, Italy) on three random points) by using the ALE procedure previously described.

The mesh was made by 400 quadrilateral elements of which 3 layers of boundary elements characterized by a stretching factor of 1.2 (increase in thickness between two consecutive boundary layers) has been applied on the top boundary.

The model was validated comparing experimental and calculated mean moisture content (whole and crust) and temperature acquired at the cake center (about $8 \mathrm{~mm}$ from the bottom), for three baking temperatures $\left(140,160\right.$ and $\left.180^{\circ} \mathrm{C}\right)$. To measure and calculate the crust mean moisture content, the first $0.003 \mathrm{~m}$ from the top were considered. The same procedure reported in section 2.1.1.1 was adopted to measure the mean moisture contents. The product temperature was monitored by using two K-type thermocouples (Chromel/Alumel; Tersid Came, Milano, Italy) arranged at $6 \mathrm{~mm}$ from the bottom). The data were sampled at a frequency of $0.25 \mathrm{~Hz}$, with a precision of $0.1{ }^{\circ} \mathrm{C}$, using the acquisition system PCI-6036E (National Instrument Corporate, Austin, TX).

\section{Results}

Concerning the inverse method results, on a PC equipped with 24 CPU (Xeon5675 64 bit $3.07 \mathrm{GHz}$ ) and $36 \mathrm{~GB}$ RAM the calculation time was $21 \mathrm{~min}$ (10 iterations). The initial parameter values were set on the base of those founded in literature $(A=10, B=8000$ and $E=4.6 \mathrm{E}-6)$ for a comparable bakery product (Baik and Marcotte, 2003). The estimated parameters values are $\mathrm{A}=7 \mathrm{E}-3, \mathrm{~B}=5100$ and $\mathrm{E}=5 \mathrm{E}-6$. The impact of the moisture concentration (parameter $\mathrm{E}$ ) appears to be very restricted and it tends to decrease with increasing the oven temperature. Similar results were achieved also by (Baik and Marcotte, 2003) who declared that the moisture content term was not significant.

The diffusivity as a function of baking time, temperature and moisture content is shown in Fig. 1. The diffusivity follows the temperature trend, increasing the cake temperature, increases also the diffusivity passing from $2.61 \mathrm{E}-10\left(\mathrm{~T}=25^{\circ} \mathrm{C}\right)$ to $7.95 \mathrm{E}-8\left(\mathrm{~T}=178^{\circ} \mathrm{C}\right) \mathrm{m}^{2} \mathrm{~s}^{-1}$. Similar values (from $1 \mathrm{E}-10$ to $6 \mathrm{E}-8 \mathrm{~m}^{2} \mathrm{~s}^{-1}$ for temperature passing from 25 to $120^{\circ} \mathrm{C}$ ) have been used by Purlis and Salvadori (2009a, 2009b) in a work on simultaneous heat and mass transfer model of bread baking. In our case, from 25 to $100^{\circ} \mathrm{C}$, a quickly augmentation of $1.38 \mathrm{E}-9 \mathrm{~m}^{2} \mathrm{~s}^{-1}$ was observed, while passing from 100 to $178^{\circ} \mathrm{C}$ a strong rise equal to $6.38 \mathrm{E}-8 \mathrm{~m}^{2} \mathrm{~s}^{-1}$ was achieved. The weak effect of the moisture content, in the range from 0.36 to $0.02 \mathrm{~kg} \mathrm{~kg}^{-1}$, can be assumed also by Fig. $1 \mathrm{~b}$. During about the first $10 \mathrm{~min}$ the moisture content quickly decreases, but the diffusivity stays constant (according to the constant temperature).

Experimental and numerical average moisture content corresponding to the minimum of (eq.32) are reported in Fig. 2. The goodness of the optimization procedure was reported in terms of determination coefficient $\left(R^{2}=0.984\right)$ and Root Mean Square Error $\left(\mathrm{RMSE}=0.014 \mathrm{~kg} \mathrm{~kg}^{-1}\right)$ calculated between experimental and numerical data.

The mean diffusivity value $\left(D=5.45 \mathrm{E}-8 \mathrm{~m}^{2} \mathrm{~s}^{-1}\right.$ ) obtained by the inverse method was compared with those reported in literature for bakery products and with that obtained by the fitting method. Regarding the fitting method, from the experimental drying data obtained at three different baking temperature $\left(140,160\right.$ and $\left.180^{\circ} \mathrm{C}\right)$, dimensionless moisture content values were calculated and fitted by using eq. (34). The effect of $n$ value on the diffusivity estimation (up to 10 terms) were considered). The optimal $n$ value was defined on the base of 

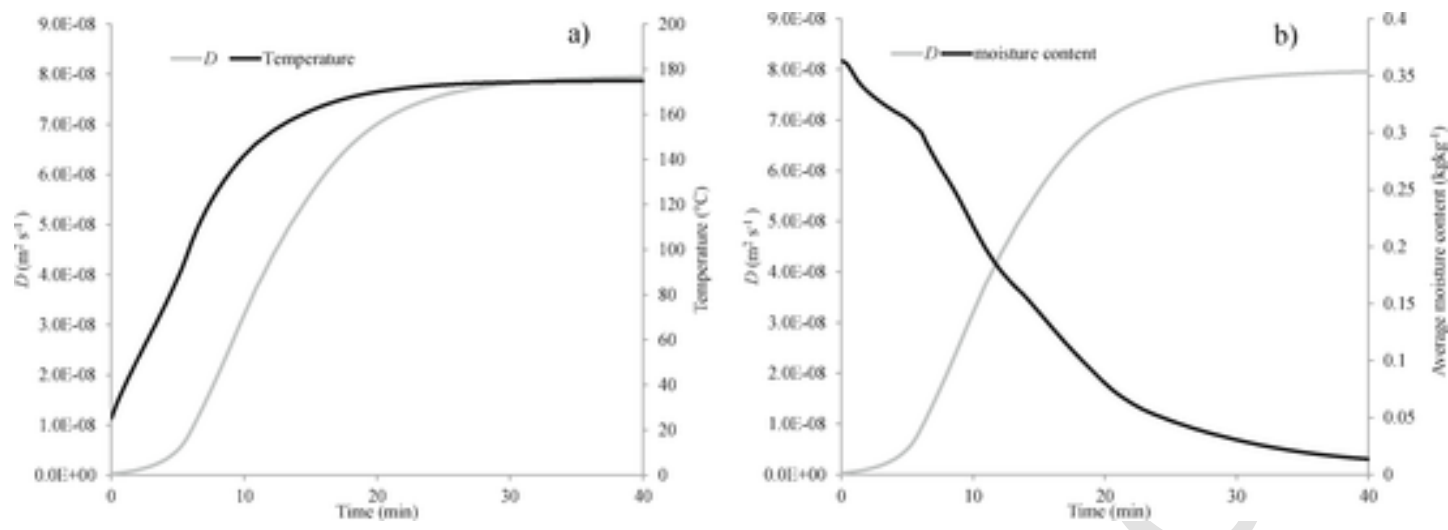

Fig. 1. Calculated diffusivity as a function of baking time, average cake temperature (a) and average moisture concentration (b).

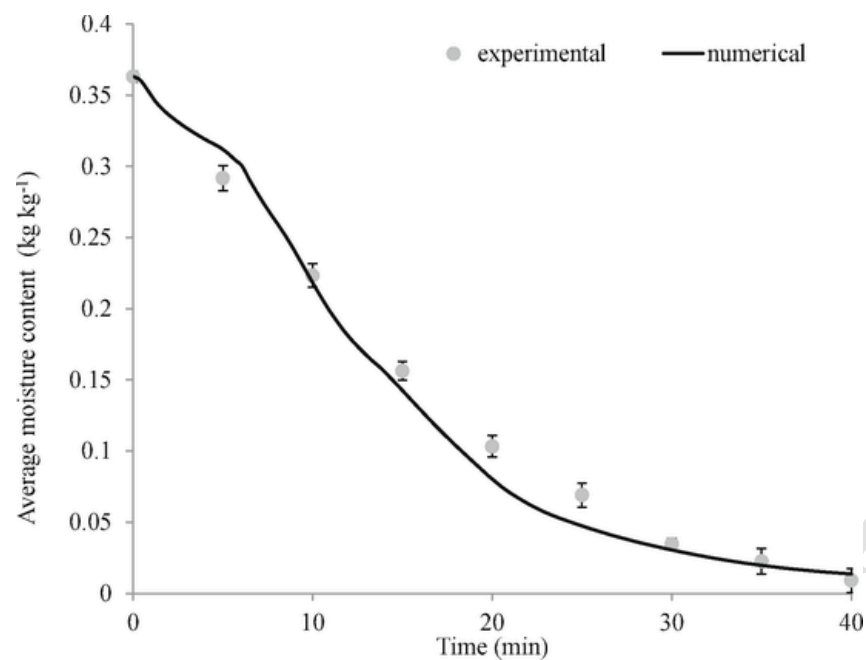

Fig. 2. Experimental (symbol) and numerical (line) average moisture content referred to the inverse method. the trend of the corresponding diffusivity value (diffusivity does not changes considering up to 5 consecutive terms, Fig. 3) and it was 9, 3 and 2 , for 140,160 and $180^{\circ} \mathrm{C}$, respectively. However, for the same oven temperature, the variation of the diffusivity value as a function of $n$ appears very restricted. The calculated constant $D$ values were $2.25 \mathrm{E}-08$, 2.36E-08 and $2.63 \mathrm{E}-08 \mathrm{~m}^{2} \mathrm{~s}^{-1}$ for 140,160 and $180^{\circ} \mathrm{C}$, respectively. The goodness of fit was assessed evaluating the determination coefficients $\left(\mathrm{R}^{2}\right)$ ranging from 0.93 to 0.98 . Moreover, in order to provide an idea of the fitting quality of the model parameter, it is important to infer the error made in obtaining the parameter values (Nicolin et al., 2016). To do this, the confidence interval in which the value is present, was evaluated. It was observed that this interval (with 95\% confidence bounds) does not change with increase of the $n$ value. The effect of the baking oven temperature on the diffusivity value was evaluated by using an Arrhenius type equation $[D=1.3 \mathrm{E}-7 \exp (-725 / T)]$. The diffusivity data obtained by the fitting method are rather comparable with those reported by (Sakin et al., 2007a) for the white cake product $(2.43 \mathrm{E}-8$ and $2.66 \mathrm{E}-8 \mathrm{~m}^{2} \mathrm{~s}^{-1}$ for oven temperature of 140 e $160^{\circ} \mathrm{C}$, respectively). Instead the mean diffusivity value $\left(D=5.45 \mathrm{E}-8 \mathrm{~m}^{2} \mathrm{~s}^{-1}\right)$ obtained by the inverse method appears to be slightly higher. Subsequently, the diffusivity obtained by the inverse method was implemented in a direct model simulating the baking of a whole cake. Experimental temperature and moisture content data were compared with those obtained by the model for different baking temperatures $\left(140,160\right.$ and $\left.180^{\circ} \mathrm{C}\right)$.

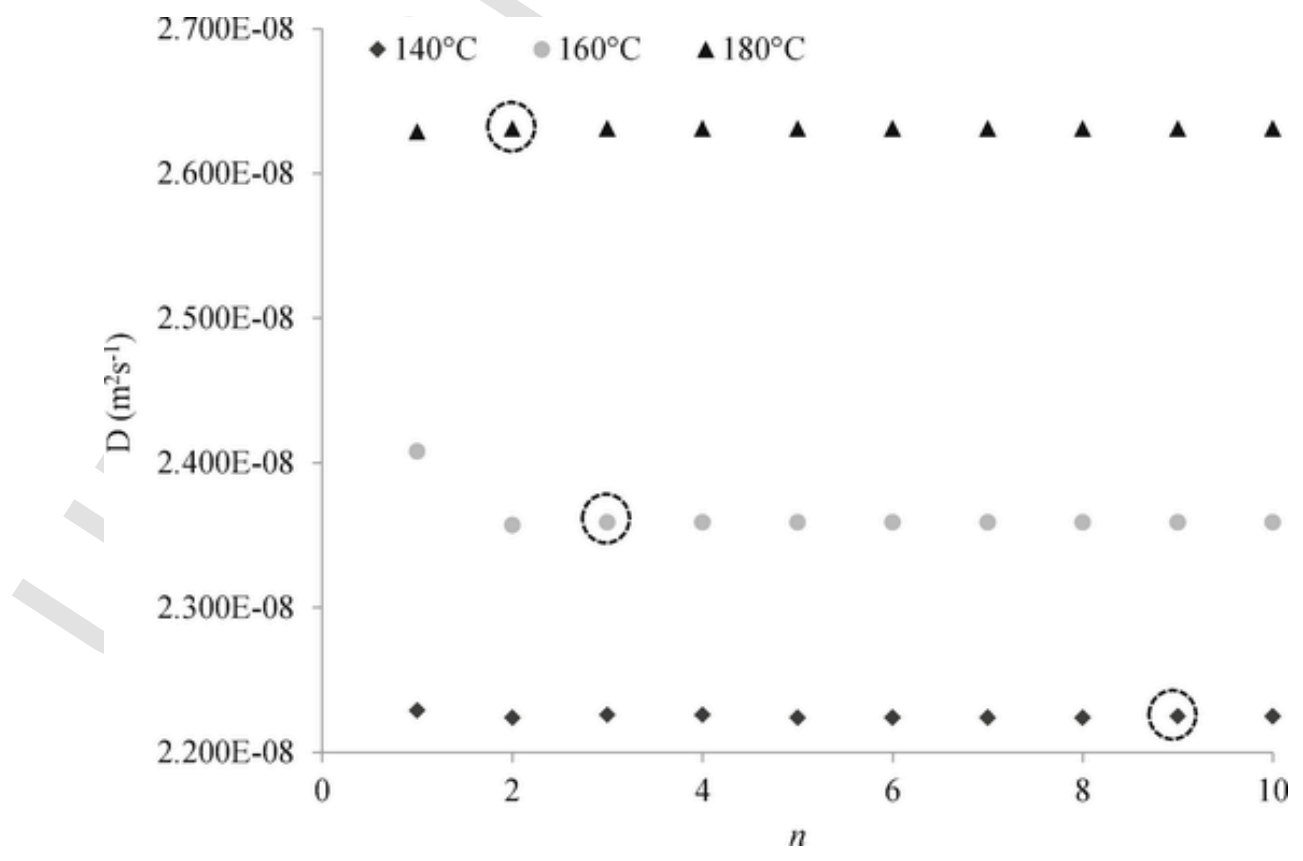

Fig. 3. Diffusivity values as function of the $n$ parameter, obtained applying the fitting method. 
Measured (mean of three replicate) and calculated temperature at $6 \mathrm{~mm}$ from the cake bottom (axial at $\mathrm{r}=0$ ) were reported in Fig. 4 for the three oven temperatures. The agreement between simulated and experimental values is reported in Table 2 in terms of determination coefficients $\left(\mathrm{R}^{2}\right)$ and Root Mean Square Error (RMSE). The best agreement was obtained at $140^{\circ} \mathrm{C}$, as suggest also by the lowest RMSE $\left(1.5^{\circ} \mathrm{C}\right)$ and greatest $\mathrm{R}^{2}(0.992)$ (data showed in Table 2 ). However also for the others two oven temperatures, good results
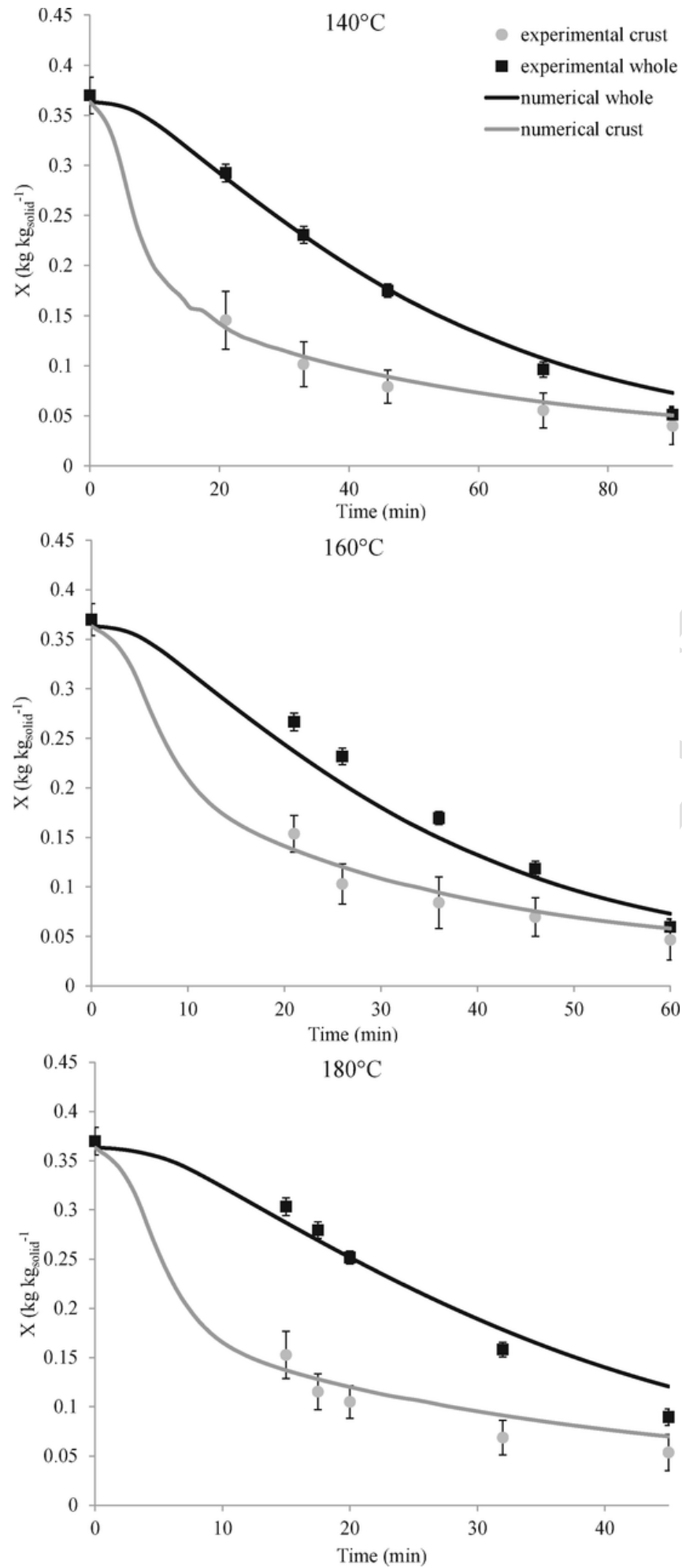

Fig. 4. Validation of the direct model: experimental (symbol) and numerical (line) average moisture contents (crust and whole cake). have been achieved. Part of the error could be probably attributed to placement of the thermocouples that could be moved during the baking.

Simulated and experimental mean moisture contents (whole and crust) over the baking times are shown in Fig. 5. It can see that for the crust the $\mathrm{R}^{2}$ are lower; this is probably due to the experimental error involved in the procedure used to separate crust from crumb which is reflected in a greater standard deviation of the experimental data.

The maximum percentage errors ranging from 3.1 to $11.8 \%$ and from 7.4 to $16.1 \%$, for temperature and moisture content validation, respectively.

The validation confirms the robustness of the diffusivity parameters obtained by the inverse method and that the developed numerical mode is able to reproduce the mass transfer phenomena during the baking cake. Consequently this model could be used to evaluate, for example, temperature and moisture content spatial distribution during the baking varying the cake dimensions and oven temperature. In this way, Figs. 6 and 7 show the spatial distribution over the time for moisture content and temperature, respectively (oven temperature of $180^{\circ} \mathrm{C}$ ). The highest temperature values were reached in the cake zones (bottom and external wall) in contact with the tray due to high thermal conductivity of the tray material. Similar behavior was reported also by Ureta et al. (2016) for the baking of sponge cake in an aluminum tray.

Regarding the moisture content, the decrease is connected with the crust formation in the cake top that it tends to increase during the baking. During the first $10 \mathrm{~min}$, it is possible to see a fast moisture decrease in the right top corner consequently to a temperature increment due to the contact with the tray (conductive effect is predominate). To confirm this behavior, during the model validation, a more surface browning was observed in this area. The thickness increment can be clearly seen in both the figures, as well as the mesh deformation (Fig. 6) according to ALE method.

As shown in Fig. 8, passing from 0 to $5 \mathrm{~min}$, a quickly thickness increment was observed (from 7 to $10 \mathrm{~mm}$ ); subsequently, the cake thickness doubles passing from 0.011 to $0.022 \mathrm{~mm}$ in about $10 \mathrm{~min}$. Finally it starts to slowly decrease and this is probably due to excessive crust formation. Very similar behavior was reported also by Le Bideau et al. (2016) and Sadeghi et al. (2016) with respect to the baking of the cake and bread, characterized by comparable dimension with those show in this study, respectively.

\section{Conclusions}

The flat cake effective moisture diffusivity in baking was determined by using the inversion of a finite element model. Simultaneous temperature and moisture content dependence was taken into account however the impact of the moisture concentration appears to be very restricted and it tends to decrease with increasing the oven temperature. The mean diffusivity value is close to those reported in literature for similar bakery products and to those obtained by the fitting method. Subsequently, the diffusivity parameters were implemented in a direct model simulating the baking of a whole realistic cake. Average experimental moisture content (crust and whole cake) and temperature data were compared with those obtained by the model for different baking temperatures confirming that the developed numerical mode is able to reproduce the heat and mass transfer phenomena during the baking cake. The advantages of proposed inverse technique is that realistic geometries (not simplified) and boundary conditions can be used and that the diffusivity may be introduced as a function of a desirable property (eg. moisture contentment, temperature, porosity).

Potentially, this could contribute to development more realistic mass transfer numerical models. Furthermore the method can be applied to many different food materials during baking.

\section{Nomenclature}

$\mu$ : :dynamic viscosity (Pa s)

$\beta$ : :air thermal expansion $\left(\mathrm{K}^{-1}\right)$

$\vartheta$ : :contact resistance $\left(\mathrm{m}^{2} \mathrm{~K} \mathrm{~W}^{-1}\right)$

$\rho:$ :density $\left(\mathrm{kg} \mathrm{m}^{-3}\right)$

aw: :water activity

$c_{p}:$ :specific heat $\left(\mathrm{Jkg}^{-1} \mathrm{~K}^{-1}\right)$

$d:$ :thickness (m) 

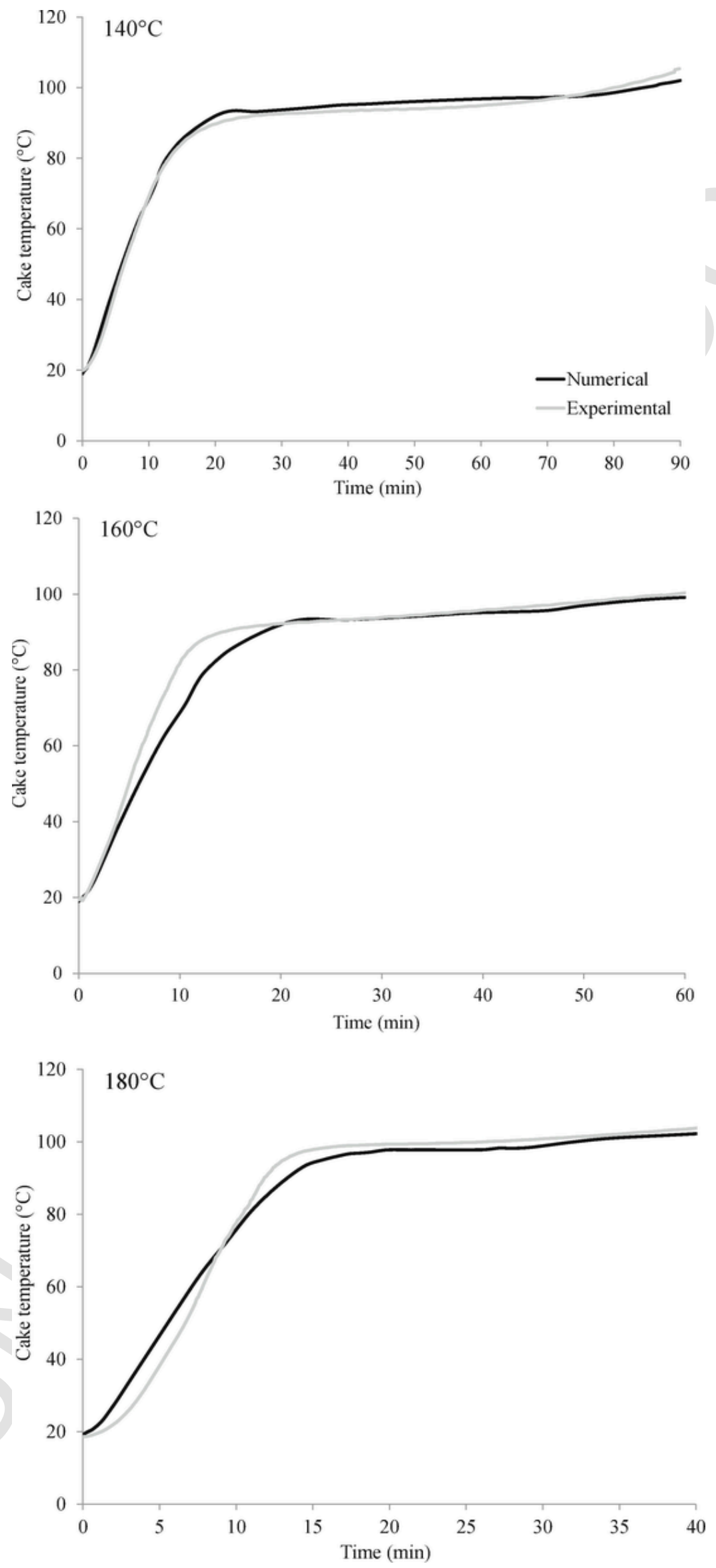
Fig. 5

Validation of the direct model: experimental (grey) and numerical (black) temperature acquired at the cake center at (6 mm from the bottom)

Table 2

Model validation results.

\begin{tabular}{|c|c|c|c|c|c|c|}
\hline & \multicolumn{2}{|c|}{ Cake temperature } & \multicolumn{2}{|c|}{ Whole cake moisture } & \multicolumn{2}{|c|}{ Crust moisture } \\
\hline & $\mathrm{R}^{2}$ & $\begin{array}{l}\text { RMSE } \\
\left({ }^{\circ} \mathrm{C}\right)\end{array}$ & $\mathrm{R}^{2}$ & $\begin{array}{l}\text { RMSE (kg } \\
\mathrm{kg}^{-1} \text { ) }\end{array}$ & $\mathrm{R}^{2}$ & $\begin{array}{l}\text { RMSE (kg } \\
\left.\mathrm{kg}^{-1}\right)\end{array}$ \\
\hline 140 & 0.992 & 1.5 & 0.996 & 0.01 & 0.981 & 0.01 \\
\hline 160 & 0.936 & 4.1 & 0.993 & 0.02 & 0.934 & 0.01 \\
\hline 180 & 0.965 & 3.4 & 0.987 & 0.02 & 0.921 & 0.02 \\
\hline
\end{tabular}

$h$ : :heat transfer coefficient $\left(\mathrm{W} \mathrm{m}^{-2} \mathrm{~K}^{-1}\right)$

$k$ : :thermal conductivity $\left(\mathrm{W} \mathrm{m}^{-1} \mathrm{~K}^{-1}\right)$

$q$ : :heat flux $\left(\mathrm{W} \mathrm{m}^{-2}\right)$

$t:$ :time (s)

C: : concentration $\left(\mathrm{mol} \mathrm{m}^{-3}\right)$
$D$ : :moisture diffusivity $\left(\mathrm{m}^{2} \mathrm{~s}^{-1}\right)$

Gr: :Grashof number

$H$ : :evaporation latent heat $\left(\mathrm{kJ} \mathrm{kg}^{-1}\right)$

$L$ : :characteristic length $(\mathrm{m})$

$N$ : :water molar flux $\left(\mathrm{mol} \mathrm{m}^{-2} \mathrm{~s}^{-1}\right)$

$\mathrm{Nu}:$ :Nusselt number

$P$ : :vapour pressure (Pa)

PM: :water molecular weight $\left(\mathrm{kg} \mathrm{mol}^{-1}\right)$

Pr: :Prandtl number

$R$ : :universal gas constant $\left(\mathrm{J} \mathrm{mol}^{-1} \mathrm{~K}^{-1}\right)$

$R a$ : :Rayleigh number

$R H$ : :relative humidity

Sc: :Schmidt numbers

Sh: :Sherwood number

T: :temperature $\left({ }^{\circ} \mathrm{K}\right)$

$X$ : :water content $\left(\mathrm{kg}_{\text {water }} \mathrm{kg}_{\text {drysolid }}{ }^{-1}\right)$

Subscripts

$a \cdot$ :air

\section{Moisture content $\left(\mathrm{kg} \mathrm{kg}^{-1}\right)$}

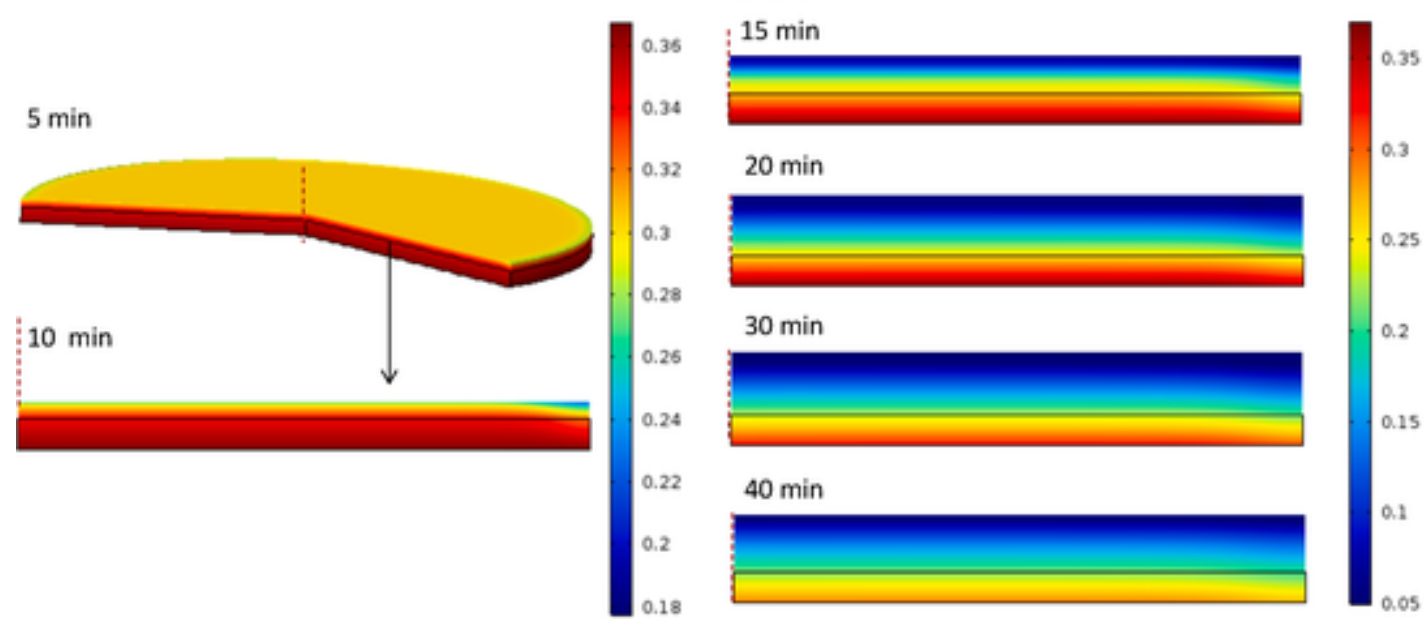

Fig. 6. Moisture distribution after $5,10,15,20$, and 45 min of baking (oven temperature: $180^{\circ} \mathrm{C}$ ) obtained by the direct model.

Temperature $\left({ }^{\circ} \mathrm{C}\right)$

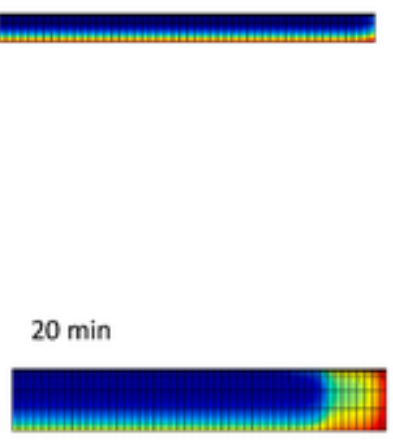

$10 \mathrm{~min}$
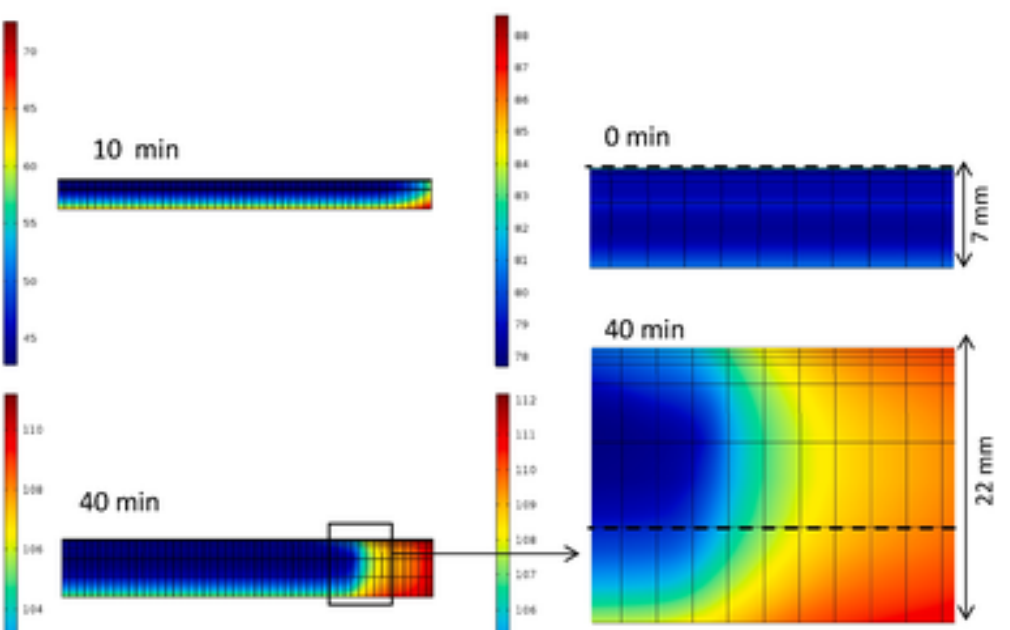

Fig. 7. Temperature distribution after $1,10,15,20$, and $45 \mathrm{~min}$ of baking (oven temperature: $180^{\circ} \mathrm{C}$ ) obtained by the direct model. 


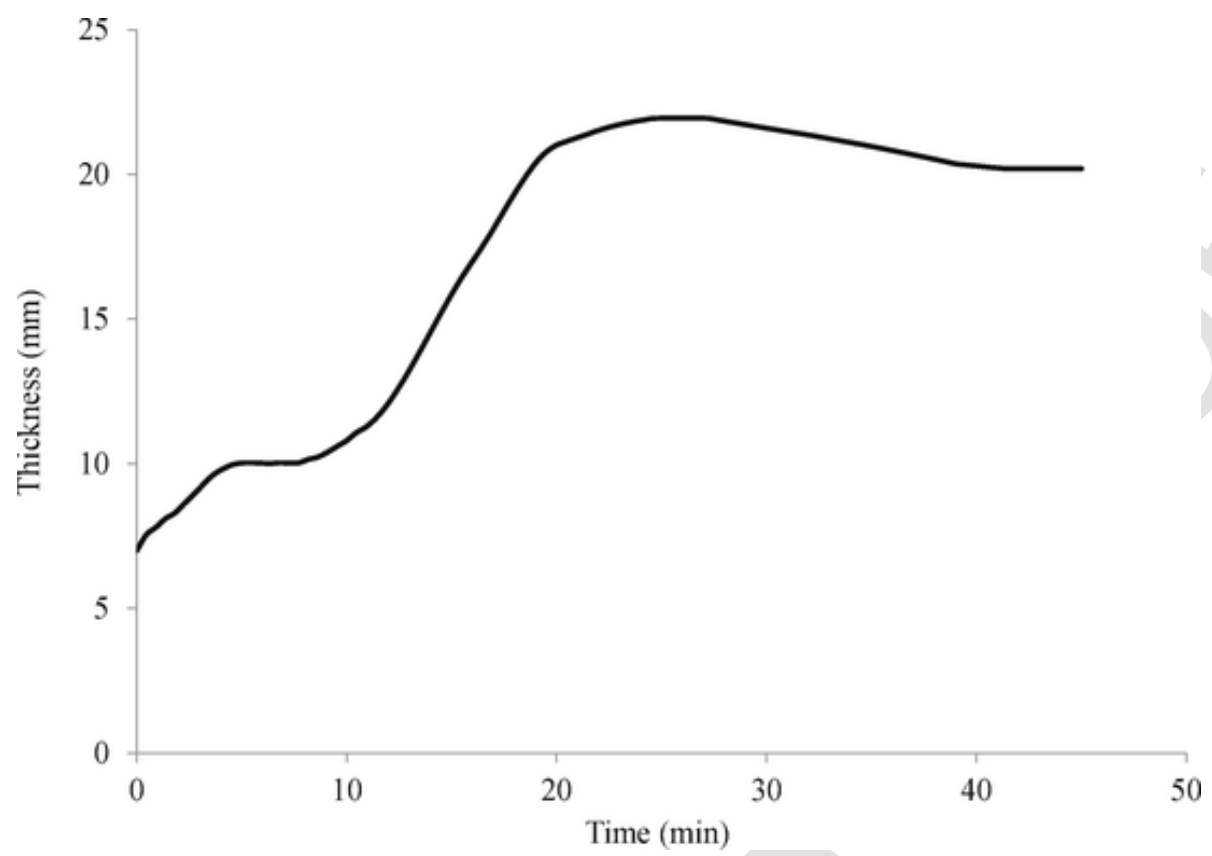

Fig. 8. Cake thickness over the baking time.

$a m b:$ :ambient
$b:$ :bottom
$c:$ :heat
$d:$ :dried
exp: :experimental
ev: :evaporation
$m:$ :mass
num: :numerical
$s:$ :surface
sat: :saturation
$t:$ top
tr: :tray
$v:$ :water vapour
$0:$ :initial
$w:$ :wall
$1:$ :before the evaporation
$2:$ :after the evaporation
$\infty::$ far from the sample
$m:$ :mass
num: :numerical
$s:$ :surface

References

Arranz, F.J., Jiménez-Ariza, T., Diezma, B., Correa, E.C., 2017. Determination of diffusion and convective transfer coefficients in food drying revisited: a new methodological approach. Biosyst. Eng. 162, 30-39. doi:10.1016/j.biosystemseng.2017.07.005.

Baik, O.D., Marcotte, M., 2003. Modeling the moisture diffusivity in a baking cake. J. Food Eng. 56, 27-36. doi:10.1016/S0260-8774(02)00144-9.

Balzarini, M.F., Reinheimer, M.A., Ciappini, C., Scienna, N.J., 2018. Mathematical model, validation and analysis of the drying treatment on quality attributes of chicory root cubes considering variable properties and shrinkage. Food Bioprod. Process. 111, 114-128.

Cevoli, C., Fabbri, A., Marai, S.V., Ferrari, E., Guarnieri, A., 2014. Estimation of thermal conductivity of short pastry biscuit at different baking stages. J. Agric. Eng. 45, 64-69.

Chhanwal, N., Tank, A., Raghavarao, K.S.M.S., Anandharamakrishnan, C., 2012. Computational fluid dynamics (CFD) modeling for bread baking process-A review. Food Bioprocess Technol. 5, 1157-1172. doi:10.1007/s11947-012-0804-y.

Crank, J., 1975. The Mathematics of Diffusion. Clarendon Press, Oxford, UK, p. 214.

Curcio, S., Aversa, M., 2009. Transport phenomena and shrinkage modeling during convective drying of vegetables. In: Proceedings of the COMSOL Conference in Milan.

da Silva, C.K.F., da Silva, Z.E., Mariani, V.C., 2009. Determination of the diffusion coefficient of dry mushrooms using the inverse method. J. Food Eng. 95, 1-10. doi:10.1016/j.jfoodeng.2009.04.009.

da Silva, W.P., Precker, J.W., Silva, C.M.D.P.S., Gomes, J.P., 2010. Determination of effective diffusivity and convective mass transfer coefficient for cylindrical solids via analytical solution and inverse method: application to the drying of rough rice. J. Food Eng. 98, 302-308. doi:10.1016/j.jfoodeng.2009.12.029.

Demirkol, E., Erdoğdu, F., Palazoğlu, T.K., 2006. Analysis of mass transfer parameters (changes in mass flux, diffusion coefficient and mass transfer coefficient) during baking of cookies. J. Food Eng. 72, 364-371. doi:10.1016/j.jfoodeng.2004.12.016.
Erdoğdu, F., 2005. Mathematical approaches for use of analytical solutions in experimental determination of heat and mass transfer parameters. J. Food Eng. 68, 233-238. doi:10.1016/j.jfoodeng.2004.05.038.

Fabbri, A., Cevoli, C., Cocci, E., Rocculi, P., 2011. Determination of the CO2 mass diffusivity of egg components by finite element model inversion. Food Res. Int. 44, 204-208. doi:10.1016/j.foodres.2010.10.035.

Fabbri, A., Cevoli, C., Troncoso, R., 2014. Moisture diffusivity coefficient estimation in solid food by inversion of a numerical model. Food Res. Int. 56, 63-67. doi:10.1016/ j.foodres.2013.12.002.

Guillard, V., Broyart, B., Bonazzi, C., Guilbert, S., Gontard, N., 2003. Moisture diffusivity in sponge cake as related to porous structure evaluation and moisture content. J. Food Sci. 68, 555-562. doi:10.1111/j.1365-2621.2003.tb05711.x.

Hamdami, N., Monteau, jY, Le BBail, A., 2004. Heat and mass transfer in par-baked bread during freezing. Food Res. Int. 37, 477-488.

Incropera, F.P., DeWitt, D.P., Bergman, T.L., Lavine, A.S., 2006. Fundamentals of Heat and Mass Transfer. sixth ed. Wiley.

Kokolj, U., Škerget, L., Ravnik, J., 2017. A numerical model of the shortbread baking process in a forced convection oven. Appl. Therm. Eng. 111, 1304-1311. doi:10.1016/ j.applthermaleng.2016.10.031.

Le Bideau, P., Cutté, R., Glouannec, P., Le Page, J.F., 2016. Numerical model for predicting heat and mass transfer phenomena during cake baking. In: Proceedings of the 2016 COMSOL Conference in Munich.

Lostie, M., Peczalski, R., Andrieu, J., Laurent, M., 2002. Study of sponge cake batter baking process. II - modeling and parameter estimation. J. Food Eng. 55, 349-357.

Lostie, M., Peczalski, R., Andrieu, J., 2004. Lumped model for sponge cake baking during the "“crust and crumb"” period. J. Food Eng. 65, 281-286.

Lucas, T., Doursat, C., Grenier, D., Wagner, M., Trystram, G., Flick, D., 2015. Modeling of bread baking with a new, multi-scale formulation of evaporation-condensation-diffusion and evidence of compression in the outskirts of the crumb. J. Food Eng. 149, 24-37. doi:10.1016/j.jfoodeng.2014.07.020.

Mariani, V.C., Lima, A.G.B., Coelho, L.S., 2008. Apparent thermal diffusivity estimation of the banana during drying using inverse method. J. Food Eng. 85, 569-579.

Nguyen, T.A., Verboven, P., Scheerlincka, N., Vandewalleb, S., Nicolal, B.M., 2006. Estimation of effective diffusivity of pear tissue and cuticle by means of a numerical water diffusion model. J. Food Eng. 72, 63-72.

Nicolas, V., Salagnac, P., Glouannec, P., Ploteau, J.P., Jury, V., Boillereaux, L., 2014. L. Modelling heat and mass transfer in deformable porous media: application to bread baking. J. Food Eng. 130, 23-35.

Nicolas, V., Glouannec, P., Ploteau, J.P., Salagnac, P., Jury, V., 2017. Experiment and multiphysics simulation of dough baking by convection, infrared radiation and direct conduction. Int. J. Therm. Sci. 115, 65-78.

Nicolin, D.J., Rossoni, D.F., Jorge, L.M.M., 2016. Study of uncertainty in the fitting of diffusivity of Fick's second law of diffusion with the use of bootstrap method. J. Food Eng. 184, 63-68. doi:10.1016/j.jfoodeng.2016.03.024.

Ousegui, A., Moresoli, C., Dostie, M., Marcos, B., 2010. Porous multiphase approach for baking process - explicit formulation of evaporation rate. J. Food Eng. 3, 535-544.

Purlis, E., 2011. Bread baking: technological considerations based on process modelling and simulation. J. Food Eng. 103, 92-102. doi:10.1016/j.jfoodeng.2010.10.003.

Purlis, E., 2014. Optimal design of bread baking: numerical investigation on combined convective and infrared heating. J. Food Eng. 137, 39-50. doi:10.1016/ j.jfoodeng.2014.03.033. 
Purlis, E., Salvadori, V.O., 2009. Bread baking as a moving boundary problem. Part 1: mathematical modelling. J. Food Eng. 91, 428-433. doi:10.1016/ j.jfoodeng.2008.09.037.

Purlis, E., Salvadori, V.O., 2009. Bread baking as a moving boundary problem. Part 2: model validation and numerical simulation. J. Food Eng. 91, 434-442. doi:10.1016/ j.jfoodeng.2008.09.038.

Sadeghi, F., Hamdami, N., Shahedi, M., Rafe, A., 2016. Numerical modeling of heat and mass transfer during contact baking of flat bread. Food Proc. Eng. 39, 345-356.

Sakin, M., Kaymak-Ertekin, F., Ilicali, C., 2007. Modeling the moisture transfer during baking of white cake. J. Food Eng. 80, 822-831. doi:10.1016/j.jfoodeng.2006.07.011.

Sakin, M., Kaymak-Ertekin, F., Ilicali, C., 2007. Simultaneous heat and mass transfer simulation applied to convective oven cupcake baking. J. Food Eng. 83, 463-474. doi:10.1016/j.jfoodeng.2007.04.007.

Seyedabadi, E., Khojastehpour, M., Abbaspour-Fard, M.H., 2017. Convective drying simulation of banana slabsconsidering non-isotropic shrinkage using FEM with the Arbitrary Lagrangian-Eulerian method. Int. J. Food Prop. 20, 36-49.
Silva, M.A.C., da Correa, J.L.G., Silva, Z.E., 2010. Application of inverse methods in the osmotic dehydration of acerola. Int. J. Food Sci. Technol. 45, 2477-2484.

Tank, A., Chhanwal, N., Indrani, D., Anandharamakrishnan, C., 2014. Computational fluid dynamics modeling of bun baking process under different oven load conditions. J. Food Sci. Technol. 51, 2030-2037. doi:10.1007/s13197-012-0736-6.

Ureta, M.M., Olivera, D.F., Salvadori, vO, 2016. Baking sponge cake: experimental characterization and mathematical modelling. Food Bioprocess Technol. 9, 664-674.

Zhang, J., Datta, A.K., 2006. Mathematical modeling of bread baking process. J. Food Eng. 75, 78-89. doi:10.1016/j.jfoodeng.2005.03.058.

Zogzas, N.P., Maroulis, Z.B., Marinos-kouris, D., 1994. Moisture diffusivity methods of experimental determination: a review. Dry. Technol. 12, 483-515. 